See discussions, stats, and author profiles for this publication at: https://www.researchgate.net/publication/269727506

\title{
A comparison of subgroup construction workers' perceptions of a safety program
}

Article in Safety Science · April 2015

DOI: 10.1016/j.scci.2014.11.021

\section{CITATIONS}

15

2 authors:

Q. Chen

The Ohio State University

42 PUBLICATIONS 436 CITATIONS

SEE PROFILE
160

Ruoyu Jin

London South Bank University

85 PUBLICATIONS 647 CITATIONS

SEE PROFILE

Some of the authors of this publication are also working on these related projects:

Project Education View project

Project Internet of Things application for facilities management and asset management of complex heritage estates View project 


\title{
A comparison of subgroup construction workers' perceptions of a safety program
}

\author{
Qian Chen ${ }^{\mathrm{a}, *}$, Ruoyu Jin ${ }^{\mathrm{b}}$ \\ ${ }^{a}$ Construction Systems Management Program, The Ohio State University, 590 Woody Hayes Dr., Columbus, OH 43210-1058, USA \\ ${ }^{\mathrm{b}}$ Department of Architecture and Built Environment, The University of Nottingham Ningbo China, SEB 323, 199 Taikang East Road, Ningbo, Zhejiang 315100, PR China
}

\section{A R T I C L E I N F O}

\section{Article history:}

Received 24 February 2013

Received in revised form 23 August 2014

Accepted 21 November 2014

Available online 13 December 2014

\section{Keywords:}

Construction industry

Safety

Specialty contractors

General contractor (GC)

\begin{abstract}
A B S T R A C T
Subcontractor safety performance has become increasingly important due to the extensive use of subcontracting in construction and the elevated safety risks. Ensuring subcontractor safety has also become a major challenge of general contractors (GC). While many GCs leave the safety responsibility to individual subcontractors, others take active roles in helping them improve safety performance. To advance the understanding of how an active approach taken by the GC is received by subcontractors, a comparative study was performed to investigate subgroup workers' perceptions of a safety program implemented by a U.S. GC among all the workers on its jobsites. In this study, a 5-dimension 28-item questionnaire was administered to 350 workers on the GC's jobsites. The collected information was used to examine differences in workers' perceptions between selected subgroups, i.e., the GC and its subcontractors as well as high- and low-risk building trades. This research found more positive perceptions of the safety program (i.e., the overall perception and the awareness and acceptance dimensions) among the GC's workers than those of the subcontractors but no difference in perceptions from high- and low-risk trades. This research also identified differences in workers' perceptions among other subgroups (e.g., based on age ranges and safety violation records) and drew insights from workers' feedback to open-ended survey questions. The findings will help contractors better understand and manage their diverse workforce to improve jobsite safety performance.
\end{abstract}

(ㄷ) 2014 Elsevier Ltd. All rights reserved.

\section{Introduction}

Subcontracting the majority of the work to specialty contractors is a strategic approach employed by general contractors (GCs) to acquire needed construction services while achieving better cost control and risk management (Hsieh, 1998). In many building projects (especially in the residential sector), about $80-90 \%$ of the work is performed by subcontractors (Silberberg, 1991; Whitten, 1991; Hinze and Tracey, 1994). As a result, their performance becomes one of the most important success-failure factors in construction projects. In many aspects such as contract management, quality control, work sequence, and information flows, managing subcontractors poses a significant challenge for GCs and construction management (CM) firms (Canter, 1993; Hinze and Tracey, 1994; Landin, 1995; Mecca, 1999; Holzemer et al., 2000; Swain and Martin, 2000).

\footnotetext{
* Corresponding author. Tel.: +1 614292 2254; fax: +1 6142929448.

E-mail addresses: chen.1399@osu.edu (Q. Chen), Ruoyu.Jin@nottingham.edu.cn (R. Jin).
}

In recent years, subcontractor safety performance has become a critical issue, receiving increasing attention in project management, safety research, and safety and health regulations (Johnstone et al., 2000; Toole, 2002; Hinze and Gambatese, 2003; Fang et al., 2006). Johnstone et al. (2000) pointed out that subcontracting increased the likelihood of multi-employer worksites, corner-cutting, dangerous forms of work disorganization, and other safety risks. Accordingly, safety and health risks associated with subcontractors emerge as significant business risks of prime contractors who are responsible for providing a safe working environment to all workers on the jobsites (Ivensky, 2008). In housing construction, the extensive use of subcontracting and the presence of a larger number of small businesses have produced many negative health and safety effects on workers (Quinlan, 2003).

The implementation of a workplace safety program is considered an effective method to prevent or reduce work-related accidents and injuries (Hislop, 1991; Tam et al., 2004; Aksorn and Hadikusumo, 2008). However, subcontractors are usually smaller companies with limited budget, time, safety resources, and understanding of legal requirements or technological developments in safety (Shaw, 1998; Wong and So, 2004). Also, smaller companies 
tend to put a lower priority on safety than larger companies and face difficulties to implement a safety program that could meet the requirements of GCs and Occupational Safety and Health Administration (OSHA) (Wilson and Koehn, 2000). To address these issues, it is not uncommon to see that some GCs or CM firms have taken active roles (e.g., enforcing specific safety requirements or even a comprehensive safety program) in helping subcontractors improve their safety management and performance.

However, implementing a site-wide safety program can be very challenging. Firstly, subcontractors hired for a project usually work in different trades. Substantial differences may exist in types of equipment they use, standards they follow, work skills and working conditions required, and many other aspects. Baradan and Usmen (2006) performed an occupational injury and fatality risk analysis on 16 building trades and found that ironworkers, roofers, brickmasons, electricians, insulation workers, carpenters, and painters \& paperhangers were high-risk trades in terms of safety; comparatively, other studied building trades had lower safety risks. Secondly, subcontractors employ a diverse workforce, consisting of various subpopulations with different backgrounds and experiences. This caused many difficulties in providing job safety and health protection for workers (CDC, 1999). Researchers have found that subgroup workers (e.g., non-union workers, immigrant workers, new workers, and certain age groups) faced higher safety and health risks (Welch et al., 2000; Fabrega and Starkey, 2001; Suruda et al., 2003; Dong and Platner, 2004; Windau and Meyer, 2005; EU-OSHA, 2006; Mah, 2007).

In the literature, there is limited research on how the active safety management approaches taken by GCs or CM firms were received by subcontractors' or subgroup workers and what the potential barriers were in implementing site-wide safety requirements or programs across a diverse workforce. This paper presents a comparative study on subgroup workers' perceptions of a safety program launched by a regional GC in the U.S. building construction industry. By combining quantitative and qualitative analysis of perception questionnaire survey results, this paper examines differences in awareness, acceptance, and other perceptions of the safety program for several pairs of subgroups, including the GC's and subcontractors' workers, high- and low-risk building trades, different age groups, etc. Thus an understanding of how a GC's safety program might be implemented in and perceived by different subgroups as well as valuable insights can be generated to improve the development and implementation of similar safety programs.

\subsection{Factors influencing GCs' and CM firms' control on subcontractor safety}

A safety study sponsored by the Construction Industry Institute revealed that generally subcontractor safety was influenced more by GCs and CM firms than by subcontractors themselves (Hinze and Figone, 1988; Hinze and Talley, 1988). This underscored the important roles that could be played by GCs and CM firms in managing subcontractor safety. However, in Chen and Jin (2012), a quantitative study on the impact of a GC's site-wide safety program showed that the program was effective in reducing accidents and safety violations among the GC's workers but had less effect on subcontractors' safety performance. This suggested that some factors might have influenced the implementation and effectiveness of this program when a diverse workforce was involved.

Besides some safety-influencing factors from subcontractors themselves, such as the risk levels of their trades, worker turnover rates, and the manner in which the training was provided (Hinze and Gambatese, 2003; Baradan and Usmen, 2006), the level of control on subcontractors' workforce was also recognized to have an impact on the effectiveness of the main contractor's safety pro- gram (Tam and Fung, 1998; Goldenhar et al., 2001). Fang et al. (2006) revealed that a less positive view of the safety climate from the employees of subcontractors or joint ventures could reduce the GC's control on its jobsites as well as the levels of worker commitment in safety. Variations in safety culture/climate have also been frequently found between other subgroups, including workers with different daily work demands and experiences (Waring, 1992), senior and junior staff (Mason and Simpson, 1995; Budworth, 1997), union and non-union workers (Gillen et al., 2002), occupational groups based on job types (McDonald et al., 2000; Glendon and Litherland, 2001), etc. Significant differences in safety climate were also identified between subgroups from different organizations (Cox and Cheyne, 2000; Lee and Harrison, 2000; McDonald et al., 2000).

Causes of different safety culture/climate are multifaceted. Most subcontractors seemed to believe that safety should be the responsibilities of prime contractors and/or design engineers, and therefore had no or little interest in safety matters (Toole, 2002; Wong and So, 2004). Inter-group variations in supervisors' safety practices (e.g., a supervisor directs workers to disregard certain safety procedures under work pressure) can create a different subunit of safety culture/climate (Zohar, 2000). Fang et al. (2006) identified significant relationships between safety climate and workers' personal characters, including age, gender, marital status, education level, safety knowledge, and individual safety behavior.

\subsection{A review of existing safety management programs and approaches}

Many different approaches can be applied by GCs or CM firms to improve jobsite safety. The common approaches adopted by various safety programs include, but may not be limited to:

- Behavior-based safety (BBS): Improve employees' safety performance by observing and inspecting pre-established safe or unsafe practices/behaviors (Geller, 1998a; Lingard and Rowlinson, 1998; DePasquale and Geller, 1999; Cooper, 2003; BSMS, 2013);

- People-based safety (PBS): Improve occupational safety and health by focusing more on people-based factors that can influence employees' attitude and organizational safety culture (Geller, 1998b; Williams, 2003; Geller and Wiegand, 2005);

- Cultural intervention: Promote safe work environments and reduce workers' unsafe behaviors by improving safety awareness, attitude, and climate (Mohamed, 2003; Nieva and Sorra, 2003; Choudhry et al., 2007a,b; Oh and Sol, 2008; Zhou et al., 2008).

While these approaches have their own pros and cons, effective safety and health management programs usually incorporate four basic components: management leadership and employee involvement, worksite analysis, hazard prevention and control, and safety and health training (Garner, 2004). In reality, not every implemented safety program was comprehensive to include all these four components. Also, big variations might exist in the implementation process. For example, in a survey of 45 non-union U.S. contractors, Goldenhar et al. (2001) found that the majority of these contractors had a formal safety program in place. However, $78 \%$ of them did not include subcontractors in their structured and/or on-the-job training due to the presence of subcontractors' own safety programs, lack of time or coordination, liability issues, etc. Although most surveyed contractors tried to pair-up experienced workers/mentors with inexperienced workers, their mentoring programs lacked formalized processes for selecting qualified mentors, coaching them on how to mentor effectively, and defining goals, time frame, and mentor compensation for these programs. 
As highlighted in the document of National Construction Agenda (CDC, 2008), the increasingly multilingual/multi-cultural nature of construction sites and the increasingly complicated management-matrices of subcontractors, vendors and prefabricators are among safety and health management challenges. It is necessary to develop and evaluate program elements and management system approaches that can address the needs of vulnerable workers. The agenda encourages performing surveys (e.g., worker perception surveys) and focus groups to understand the current use and effectiveness of safety and health management programs.

\section{The GC's safety management program studied in this paper}

The studied safety program was developed by the GC to (1) improve workers' safety awareness, attitude, accountability and involvement in safety management, and (2) reduce injuries and workers' exposure to "Focus 4 Hazards" (i.e., falls, electrocution, struck-by, and caught-in/between) defined by OSHA (2011). This ongoing program was initially launched on the GC's jobsites at the end of May 2008 after related training was given to both the GC's and subcontractors' employees. Since its inception, safety and accountability (i.e., workers being held responsible for safety violations) have been continuously enforced among the GC's employees, all hired subcontractors, and material suppliers at all tiers.

The program emphasizes three basic safety management elements: (1) $100 \%$ eye protection (i.e., workers wearing safety glasses at all times on the project except during scheduled breaks away from potential eye hazards or while in a trailer), (2) daily "huddle" (toolbox) meetings, and (3) accountability for 20 non-negotiable unsafe behaviors identified to have close relationships with the "Focus 4 Hazards". Each hazard category contains five non-negotiables, which are all OSHA violations. For example, "working at heights of 6 feet or greater with no approved fall protection" and "improperly using a step ladder" are two of the five non-negotiables under the falls category. "Working within 10 feet of power lines" is a non-negotiable under the electrical category. More details about the 20 non-negotiables can be found in Chen and Jin (2012).

In this program, safety representatives and management staff are required to report workers' violations on 20 non-negotiable behaviors. Workers are also strongly encouraged to report violations from their peers. The penalty for those who commit a firsttime violation is "being immediately removed from the jobsite for one day". However, they can return to job the following morning to lead the "huddle" meeting and sign an engagement letter. A second-time violation by the same person would lead to different consequences: The GC's workers will be separated from the GC without pay and benefits for 30 days but are eligible for rehiring; subcontractor's workers will not be allowed to work on the GC's projects for one year. For subcontractors having a higher number of violations, they are required to have a plan of correction and a full-time safety specialist or competent person on the project at their own cost.

Chen and Jin (2012) reported that this safety program had successfully reduced accidents and safety violations among the GC's workers but had less effect on subcontractors' safety performance. This raised specific questions: How was this program received by the diverse workforce of subcontractors and what might affect its effectiveness among these workers? A well-designed and executed worker perception survey would provide valuable insights to help answer these questions.

\section{Research methodology}

This study compared subgroups' perceptions of the studied safety program. The purpose was to: (1) test the hypothesis that perception variations existed between subgroup workers; (2) explore potential causes of such differences; and (3) offer insights for contractors to improve the effectiveness of their safety programs across a diverse workforce. This study developed a comprehensive questionnaire to survey workers on the GC's jobsites. The 28 survey questions were in multiple-choice, Likert scale, and open-ended formats. Except for the general background questions and open-ended questions to solicit feedback, the remaining survey questions were grouped into five dimensions: awareness, accountability, acceptance, general safety attitude, and schedule impact. To ensure the relevance and accuracy of the questionnaire, the GC's feedback was sought and incorporated into the revision of the questionnaire. The approval from the University Institutional Review Board was obtained before the start of the survey.

To ensure wide participation and thoughtful response from workers, the face-to-face survey approach was adopted. From November 2010 to January 2011, researchers visited the GC's 31 construction sites, spanning six regions in four states. Up to 350 workers were surveyed. Most of the interviews were conducted in the GC's trailers while some were performed in the field. Each time, 3-5 workers were brought in by a GC's safety coordinator and left alone with researchers. The workers were given choices to fill in questionnaires by themselves or take a one-on-one interview with one of the researchers. In the latter option, the researcher asked a worker questions and recorded his/her responses on the questionnaire. This was beneficial to workers with low literacy levels. Questionnaires finished by workers themselves were checked by researchers to ensure that open-ended questions received adequate responses. Translated questionnaires were also provided for 11 Spanish-speaking workers.

The collected information was entered into a computer and sorted separately for different subgroups, including the GC, subcontractors, high-risk trades, and low-risk trades. After evaluating the distribution and frequency ranking of different types of safety violations reported from May 2008 to December 2011 (Chen and Jin, 2012), this research categorized roofing, steel, masonry, insulation, drywall, and mechanical workers as high-risk trades because they frequently work at height and committed most of fall-related violations. All other workers (e.g., concrete workers, carpenters, excavators, rebar installers, operators, and others not specified in the survey) were classified as low-risk trades. This categorization was agreed by the GC. This research selected 15 survey questions to calculate overall perception scores for different subgroups. Since the selected questions fell into four dimensions (awareness, accountability, acceptance, and general safety attitude), subgroup scores for each of these dimensions were also computed. The schedule impact dimension was not included in the calculation of perception scores because answers to these questions were not necessarily positive or negative perceptions.

The non-parametric Wilcoxon Rank-Sum (WRS) test, the Inference Concerning Two Means with a t-distribution test (ICTM-t), and the Two-proportion Z-test (Johnson, 2005) were performed to examine subgroup differences. WRS holds more power than the $t$-test in studying non-normally distributed data (Bridge and Sawilowsky, 1999). It was applied to compare subgroup workers' perception scores on each dimension and individual questions under each dimension. ICTM-t was adopted to compare subgroups' overall perception scores, which were likely to be continuously and normally distributed. The Two-proportion Z-test was used to analyze questions not included in the calculation of perception scores. All the statistical tests used a two-tailed approach based on the same null hypothesis that subgroups had the same mean or median value using the $5 \%$ level of significance. The alternative hypothesis was that subgroups had different perceptions on the studied question, dimension, or the overall perception. While the $p$ values were used to determine whether statistically significant 
differences existed between paired subgroups, the $\mathrm{z}$ scores indicated the direction of difference for comparison subgroups with statistical differences.

Besides the two pairs of subgroups this study focused on, a few other subgroups were also analyzed by using the ICTM- $t$ test. They were created based on (1) different age ranges (younger than 30 , $30-49$, and above 50), (2) whether or not the workers had worked on multiple projects with the GC, and (3) whether or not they had been asked to leave the GC's jobsites due to a safety violation. Furthermore, responses to open-ended questions were analyzed and compared between the GC's and subcontractors' workers using content analysis and statistical tests. First, repeatedly mentioned keywords or phrases were identified by adopting a method of coding for explicit concepts. Then, relational analysis was used to verify the relevance of those keywords or phrases and to determine their relationships and categorization. Lastly, subgroup differences were identified through frequency counts and the two-tailed Twoproportion Z-test.

\section{Results}

\subsection{Characteristics of subgroup workers}

Of 350 workers surveyed in this study, $31 \%$ of them were the GC's employees $(N=110)$ while the remaining $69 \%$ were from subcontractors hired by the GC $(N=240)$. Furthermore, $41 \%$ of the workers surveyed were in high-risk trades $(N=145)$ and the remaining $59 \%$ were in low-risk trades $(N=205)$. Table 1 summarizes the characteristics of these subgroups.

This study found that only $12 \%$ of the GC's workers worked in high-risk trades compared to $53 \%$ of subcontractors' workers working in these trades. The rest of the GC's and subcontractors' workers worked in low-risk trades. The statistical analysis confirmed that more subcontractors' workers worked in high-risk trades while more GC's workers worked in low-risk trades. Compared with subcontractors, the GC tended to have more old workers (above 50). In addition, 90\% of the GC's workers had worked on multiple projects with the GC while only $62 \%$ of subcontractors' workers had done so. This implied that the GC's workers might have had more exposure to the safety program than workers of subcontractors, which led to their increased awareness of the program. Both subgroups had a similar portion of workers who had been asked to leave the GC's jobsites due to safety violations. So if they had biased views on the program, the influences on the final survey results would be very similar for both subgroups.

For high-risk trades, only $10 \%$ of their workers were from the GC while $90 \%$ were from subcontractors. This seems to be aligned with a common perception in the field that most high-risk jobs are performed by subcontractors. Compared to high-risk trades, low-risk trades had slightly lower percentage of middle-aged workers. In addition, high-risk trades had a lower percentage of workers (62\%) who had worked on multiple projects with the GC when compared to low-risk trades (77\%). No statistical difference was found between the two subgroups in percentage of workers who had been asked to leave the GC's jobsite due to safety violations.

\subsection{Comparison between subgroups' perception scores}

\subsubsection{Dimension one: awareness of the safety program}

Awareness questions in the survey asked the workers how aware they were of the GC's safety program, its three basic elements, and the 20 non-negotiable unsafe behaviors, respectively. Results related to each subgroup and subgroup comparisons are shown in Table 2. It can be seen that the GC's workers had a better awareness of the non-negotiable behaviors than subcontractors' workers (as shown in the bolded $p$ values). The GC's workers also outperformed the subcontractors' in the overall awareness as evidenced by a $p$ value of 0.004 . No difference in workers' awareness of the safety program was found between the high- and low-risk subgroups.

Workers who had some awareness of the 20 non-negotiable behaviors were asked to identify their ways of learning this information among four possible choices: (1) training (classroom and/or orientation video), (2) visuals (e.g., banners, flags, posters, hardhat stickers, tapes, etc.), (3) both training and visuals, and (4) others. Based on the data analysis, workers who learned through both training and visuals were likely to know more non-negotiables than workers only learning in one way or the other. Specifically, among workers who learned in both formats, $36 \%$ of them knew all 20 non-negotiables, 49\% knew most of them, and 15\% knew a few of them. In contrast, among workers who only learned through one way or the other, the percentage of those aware of all or most of 20 non-negotiables was lower (31\% and 39\%, respectively), and the percentage of workers knowing only a few non-negotiables

Table 1

Characteristics of workers for subgroups compared.

\begin{tabular}{|c|c|c|c|c|}
\hline \multirow[t]{2}{*}{ Characteristics } & \multicolumn{2}{|c|}{ GC's vs. subcontractors' workers } & \multicolumn{2}{|c|}{ High-risk vs. low-risk trades } \\
\hline & GC (\% of workers) & Subcontractors (\% of workers) & High-risk (\% of workers) & Low-risk (\% of workers) \\
\hline $\begin{array}{l}\text { High-risk trade workers } \\
z \text {-score } / p \text { value }^{a}\end{array}$ & $\begin{array}{l}12 \% \\
(-7.18) / 0.000\end{array}$ & $53 \%$ & - & - \\
\hline Low-risk trade workers & $88 \%$ & $47 \%$ & - & - \\
\hline GC's workers & - & - & $10 \%$ & $46 \%$ \\
\hline $\begin{array}{l}\text { Subcontractors' workers } \\
z \text { score } / p \text { value }\end{array}$ & - & - & $\begin{array}{l}90 \% \\
(-7.05) / 0.000\end{array}$ & $54 \%$ \\
\hline $\begin{array}{l}\text { Age: Younger than } 30 \\
z \text { score } / p \text { value }\end{array}$ & $\begin{array}{l}29 \% \\
(-0.28) / 0.780\end{array}$ & $31 \%$ & $\begin{array}{l}26 \% \\
(-1.32) / 0.186\end{array}$ & $33 \%$ \\
\hline $\begin{array}{l}\text { Between } 30 \text { and } 49 \\
z \text { score } / p \text { value }\end{array}$ & $\begin{array}{l}50 \% \\
(-1.31) / 0.190\end{array}$ & $57 \%$ & $\begin{array}{l}63 \% \\
\mathbf{2 . 3 5} / \mathbf{0 . 0 1 8 0}\end{array}$ & $50 \%$ \\
\hline $\begin{array}{l}\text { Above } 50 \\
\quad z \text { score } / p \text { value }\end{array}$ & $\begin{array}{l}21 \% \\
\mathbf{2 . 1 9} / \mathbf{0 . 0 2 8}\end{array}$ & $12 \%$ & $\begin{array}{l}11 \% \\
-1.59 / 0.112\end{array}$ & $17 \%$ \\
\hline $\begin{array}{l}\text { Worked on multiple projects with the GC } \\
z \text { score } / p \text { value }\end{array}$ & $\begin{array}{l}90 \% \\
5.25 / 0.000\end{array}$ & $62 \%$ & $\begin{array}{l}62 \% \\
(-2.95) / 0.004\end{array}$ & $77 \%$ \\
\hline $\begin{array}{l}\text { Had been asked to leave the GC's jobsite } \\
z \text { score } / p \text { value }\end{array}$ & $\begin{array}{l}9 \% \\
0.67 / 0.502\end{array}$ & $7 \%$ & $\begin{array}{l}10 \% \\
1.14 / 0.254\end{array}$ & $6 \%$ \\
\hline
\end{tabular}

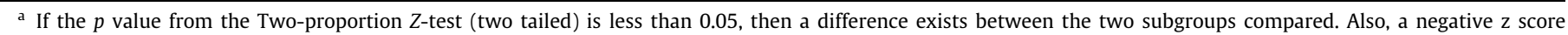

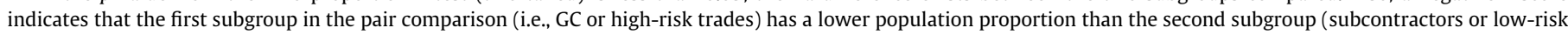
trades), and vice versa. 
Table 2

Awareness of the safety program and its key elements.

\begin{tabular}{|c|c|c|c|c|}
\hline \multirow[t]{2}{*}{ Response } & \multicolumn{2}{|c|}{ GC's vs. subcontractors' workers } & \multicolumn{2}{|c|}{ High-risk vs. low-risk trades } \\
\hline & GC (\% of workers) & Subcontractors (\% of workers) & High-risk (\% of workers) & Low-risk (\% of workers) \\
\hline \multicolumn{5}{|c|}{ I. Are you aware of the GC's safety program? } \\
\hline Yes $\left(1^{\mathrm{a}}\right)$ & $100 \%$ & $98 \%$ & $100 \%$ & $98 \%$ \\
\hline No $(0)$ & $0 \%$ & $2 \%$ & $0 \%$ & $2 \%$ \\
\hline$z$ score $/ p$ value $(\text { WRS })^{\mathrm{b}}$ & $0.25 / 0.802$ & & $0.31 / 0.756$ & \\
\hline \multicolumn{5}{|c|}{ II. Which of the three basic elements of the program are you familiar with (choose all that apply)? } \\
\hline None of them $(0)$ & $0 \%$ & $1 \%$ & $1 \%$ & $1 \%$ \\
\hline One of them $(0.33)$ & $7 \%$ & $12 \%$ & $12 \%$ & $9 \%$ \\
\hline Two of them (0.67) & $12 \%$ & $16 \%$ & $12 \%$ & $15 \%$ \\
\hline All of them (1) & $81 \%$ & $71 \%$ & $75 \%$ & $75 \%$ \\
\hline$z$ score/p value (WRS) & $1.70 / 0.092$ & & $0.07 / 0.948$ & \\
\hline \multicolumn{5}{|c|}{ III. Are you aware of the 20 non-negotiable behaviors listed in the accountability element of the program? } \\
\hline No idea about them $(0)$ & $2 \%$ & $10 \%$ & $6 \%$ & $8 \%$ \\
\hline Aware of a few of them (0.33) & $15 \%$ & $22 \%$ & $19 \%$ & $21 \%$ \\
\hline Aware of most of them (0.67) & $45 \%$ & $38 \%$ & $42 \%$ & $42 \%$ \\
\hline Aware of all of them (1) & $38 \%$ & $30 \%$ & $33 \%$ & $29 \%$ \\
\hline$z$ score/p value (WRS) & $3.19 / 0.002$ & & $0.86 / 0.392$ & \\
\hline \multicolumn{5}{|l|}{ Overall for “Awareness" } \\
\hline$z$ score $/ p$ value (WRS) & 2.91/0.004 & & $0.59 / 0.553$ & \\
\hline
\end{tabular}

a The number denotes the score assigned for selecting this option.

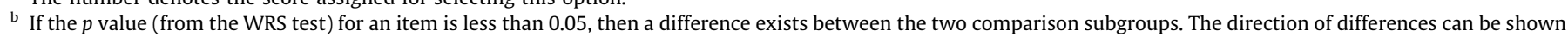
by the related $z$ score. A positive $z$ score indicates that the first subgroup in the pair comparison (i.e., GC or high-risk group) had a higher score than the second subgroup (subcontractors or low-risk group), and vice versa.

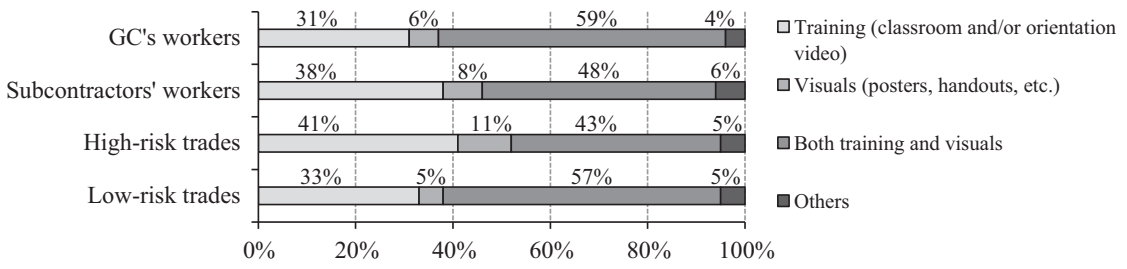

Fig. 1. Ways of learning 20 non-negotiable behaviors.

increased (27\%). In addition, $3 \%$ of these workers were completely unaware of these non-negotiables.

Fig. 1 illustrates how subgroups' workers learned the 20 nonnegotiable behaviors. It can be seen that $59 \%$ of the GC's workers learned this information through both training and visuals compared with $48 \%$ of subcontractors' workers who did so, although no statistical difference was identified between these two subgroups ( $p$ value $=0.062$ ). In contrast, this study found that a higher percentage of low-risk trade workers were provided with a more effective means of learning non-negotiables compared to high-risk trade workers $(p$ value $=0.012$ ).

\subsubsection{Dimension two: accountability for safety}

Accountability questions aimed to test workers' understanding of their safety responsibility and the consequences of safety violations. Results related to each subgroup and subgroup comparisons are shown in Table 3. Among the two pairs of subgroups compared, no statistical differences were found in the accountability

Table 3

Understanding of safety responsibility and consequences of safety violations.

\begin{tabular}{|c|c|c|c|c|}
\hline \multirow[t]{2}{*}{ Response } & \multicolumn{2}{|c|}{ GC's vs. subcontractors' workers } & \multicolumn{2}{|l|}{ High-risk vs. low-risk trades } \\
\hline & GC (\% of workers) & Subcontractors (\% of workers) & High-risk (\% of workers) & Low-risk (\% of workers) \\
\hline \multicolumn{5}{|c|}{ I. Do you understand how you will be held responsible for violating one of the 20 non-negotiables? } \\
\hline Yes $(1)$ & $95 \%$ & $87 \%$ & $93 \%$ & $86 \%$ \\
\hline No $(0)$ & $5 \%$ & $13 \%$ & $7 \%$ & $14 \%$ \\
\hline$z$ score/p value (WRS) & $1.28 / 0.200$ & & $1.00 / 0.318$ & \\
\hline \multicolumn{5}{|c|}{ II. a. What is the consequence of a first-time violation? } \\
\hline Know the right consequence $(0.5)$ & $65 \%$ & $56 \%$ & $61 \%$ & $56 \%$ \\
\hline Do not know $(0)$ & $35 \%$ & $44 \%$ & $39 \%$ & $44 \%$ \\
\hline$z$ score/p value (WRS) & $0.92 / 0.360$ & & $0.77 / 0.444$ & \\
\hline \multicolumn{5}{|c|}{ b. What is the consequence of a second-time violation? } \\
\hline Know the right consequence $(0.5)$ & $38 \%$ & $35 \%$ & $35 \%$ & $36 \%$ \\
\hline Do not know $(0)$ & $62 \%$ & $65 \%$ & $65 \%$ & $64 \%$ \\
\hline$z$ score/p value (WRS) & $0.77 / 0.442$ & & $(-0.03) / 0.976$ & \\
\hline \multicolumn{5}{|l|}{ Overall for "accountability" } \\
\hline$z$ score/p value (WRS) & $1.86 / 0.062$ & & $0.81 / 0.418$ & \\
\hline
\end{tabular}




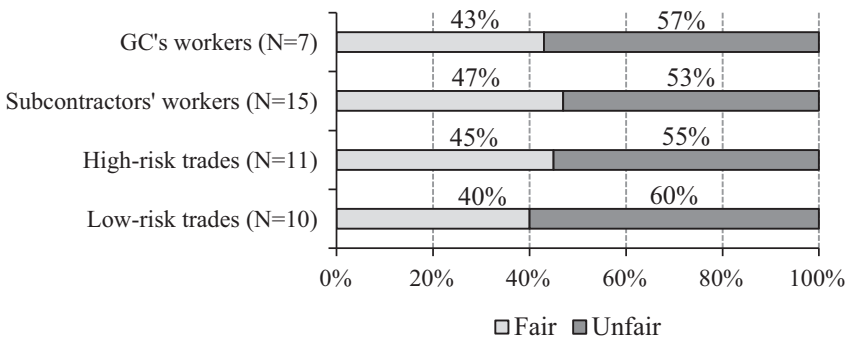

Fig. 2. Fairness of safety violation consequences. dimension. The findings for knowing the consequences of violation are consistent. For all the four subgroups, the majority of workers (ranging from 56\% to 65\%) knew the right consequence of a firsttime violation. However, the percentage of workers who knew the right consequence of a second-time violation was significantly reduced in four subgroups, only ranging from 35\% to $38 \%$.

It was assumed that individual workers' perceptions of the safety program might be affected if they had committed a safety violation and been penalized before. However, this might have also put them in a better position to share their feelings regarding the program's enforcement and the fairness of the consequences. In

Table 4

Acceptance of the safety program and its effectiveness.

\begin{tabular}{|c|c|c|c|c|}
\hline \multirow[t]{2}{*}{ Response } & \multicolumn{2}{|c|}{ GC's vs. subcontractors' workers } & \multicolumn{2}{|l|}{ High-risk vs. low-risk trades } \\
\hline & GC (\% of workers) & Subcontractors (\% of workers) & High-risk (\% of workers) & Low-risk (\% of workers) \\
\hline \multicolumn{5}{|c|}{ I. Do you feel that the safety program has increased employees' safety awareness on the GC's jobsites? } \\
\hline Significantly increased (1) & $44 \%$ & $45 \%$ & $52 \%$ & $39 \%$ \\
\hline Slightly increased $(0.5)$ & $54 \%$ & $50 \%$ & $45 \%$ & $56 \%$ \\
\hline Not increased at all $(0)$ & $2 \%$ & $5 \%$ & $3 \%$ & $5 \%$ \\
\hline$z$ score/p value (WRS) & $0.07 / 0.944$ & & 2.44/0.012 & \\
\hline \multicolumn{5}{|c|}{ II. Do you feel that the GC's safety program contributes to a safer work site? } \\
\hline Contributed to a safer work site (1) & $97 \%$ & $95 \%$ & $97 \%$ & $95 \%$ \\
\hline Not contributed to a safer site $(0)$ & $3 \%$ & $5 \%$ & $3 \%$ & $5 \%$ \\
\hline$z$ score $/ p$ value (WRS) & $0.33 / 0.742$ & & $0.20 / 0.842$ & \\
\hline \multicolumn{5}{|c|}{ III. If you have worked on multiple projects of the GC, has safety been enforced consistently? } \\
\hline Enforced consistently (1) & $67 \%$ & $65 \%$ & $66 \%$ & $65 \%$ \\
\hline Not enforced consistently (0) & $33 \%$ & $35 \%$ & $34 \%$ & $35 \%$ \\
\hline$z$ score $/ p$ value (WRS) & $0.19 / 0.848$ & & $0.54 / 0.586$ & \\
\hline \multicolumn{5}{|c|}{ IV. What best describes your feeling about how the safety program is enforced? } \\
\hline Genuine attempt to keep workers safe (1) & $76 \%$ & $74 \%$ & $77 \%$ & $73 \%$ \\
\hline Negative perception(s) (0) & $24 \%$ & $26 \%$ & $23 \%$ & $27 \%$ \\
\hline$z$ score $/ p$ value (WRS) & $0.28 / 0.780$ & & $0.46 / 0.666$ & \\
\hline \multicolumn{5}{|c|}{ V. a. Please measure the effectiveness of " $100 \%$ requirement for safety glass" in creating a safer work environment } \\
\hline Very effective $(1 / 3)$ & $64 \%$ & $60 \%$ & $63 \%$ & $61 \%$ \\
\hline Somewhat effective $(1 / 6)$ & $24 \%$ & $23 \%$ & $22 \%$ & $24 \%$ \\
\hline Neutral $(0)$ & $5 \%$ & $11 \%$ & $8 \%$ & $10 \%$ \\
\hline Somewhat ineffective $(-1 / 6)$ & $2 \%$ & $2 \%$ & $2 \%$ & $2 \%$ \\
\hline Very ineffective $(-1 / 3)$ & $5 \%$ & $4 \%$ & $5 \%$ & $3 \%$ \\
\hline$z$ score/p value (WRS) & $0.76 / 0.448$ & & $0.07 / 0.946$ & \\
\hline \multicolumn{5}{|c|}{ b. Please measure the effectiveness of "daily huddle meeting" in creating a safer work environment } \\
\hline Very effective $(1 / 3)$ & $42 \%$ & $28 \%$ & $31 \%$ & $35 \%$ \\
\hline Somewhat effective $(1 / 6)$ & $39 \%$ & $26 \%$ & $29 \%$ & $31 \%$ \\
\hline Neutral $(0)$ & $14 \%$ & $31 \%$ & $29 \%$ & $23 \%$ \\
\hline Somewhat ineffective $(-1 / 6)$ & $2 \%$ & $6 \%$ & $3 \%$ & $6 \%$ \\
\hline Very ineffective $(-1 / 3)$ & $3 \%$ & $9 \%$ & $8 \%$ & $5 \%$ \\
\hline$z$ score/p value (WRS) & 4.09/0.000 & & $(-0.29) / 0.772$ & \\
\hline \multicolumn{5}{|c|}{ c. Please measure the effectiveness of "accountability/20 non-negotiables" in creating a safer work environment } \\
\hline Very effective $(1 / 3)$ & $50 \%$ & $37 \%$ & $43 \%$ & $40 \%$ \\
\hline Somewhat effective $(1 / 6)$ & $31 \%$ & $24 \%$ & $24 \%$ & $28 \%$ \\
\hline Neutral $(0)$ & $13 \%$ & $30 \%$ & $28 \%$ & $23 \%$ \\
\hline Somewhat ineffective $(-1 / 6)$ & $4 \%$ & $4 \%$ & $1 \%$ & $5 \%$ \\
\hline Very ineffective $(-1 / 3)$ & $2 \%$ & $5 \%$ & $4 \%$ & $4 \%$ \\
\hline$z / p$ value (WRS) & $2.67 / 0.008$ & & $0.34 / 0.734$ & \\
\hline \multicolumn{5}{|c|}{ VI. How would you rate the GC's safety program compared to other company's safety program? } \\
\hline Better $(1)$ & $75 \%$ & $41 \%$ & $52 \%$ & $50 \%$ \\
\hline The same $(0)$ & $22 \%$ & $52 \%$ & $42 \%$ & $44 \%$ \\
\hline Not as effective $(-1)$ & $3 \%$ & $7 \%$ & $6 \%$ & $6 \%$ \\
\hline$z / p$ value (WRS) & 4.91/0.000 & & $0.23 / 0.814$ & \\
\hline \multicolumn{5}{|c|}{ VII. Do you feel safer on the GC's jobsites as compared to other jobsites you have worked on? } \\
\hline Much safer (1) & $46 \%$ & $25 \%$ & $35 \%$ & $29 \%$ \\
\hline Safer $(0.5)$ & $37 \%$ & $27 \%$ & $28 \%$ & $31 \%$ \\
\hline Same $(0)$ & $15 \%$ & $40 \%$ & $31 \%$ & $34 \%$ \\
\hline Less safe $(-0.5)$ & $2 \%$ & $5 \%$ & $4 \%$ & $4 \%$ \\
\hline Much less safe $(-1)$ & $0 \%$ & $3 \%$ & $2 \%$ & $2 \%$ \\
\hline$z / p$ value (WRS) & $5.23 / 0.000$ & & $0.92 / 0.358$ & \\
\hline \multicolumn{5}{|l|}{ Overall for "acceptance"a } \\
\hline$z / p$ value (WRS) & $4.28 / 0.000$ & & $0.87 / 0.386$ & \\
\hline
\end{tabular}

a The overall acceptance score used in the statistical analysis excludes item III, for which the sample size $(N=257)$ is smaller than that for other items. This is because only workers who had worked on multiple GC's projects were requested to answer this question. 
this study, workers who self-claimed to have committed a prior violation were asked about the fairness of the consequences. Fig. 2 compares the views of these workers in different subgroups. It can be seen that in all of the subgroups, more than half of these workers felt that the penalties were unfair. The percentages seemed to be slightly higher in the GC and low-risk trades groups and lower in the subcontractors and high-risk trades groups. One reason for more low-risk trade workers complaining about the consequences might be that they were more likely to commit minor violations (such as not being protected by a Ground Fault Circuit Interrupter [GFCI]). Hence the consequences seemed to be so harsh to them. However, the statistical analysis results did not show any difference between the GC's and subcontractors' workers ( $p$ value $=0.912$ ) as well as between high- and low-risk trades ( $p$ value $=0.802$ ). The accuracy of such analyses was limited due to small sample sizes.

\subsubsection{Dimension three: acceptance of the safety program}

Acceptance questions sought workers' opinion of the safety program in the following aspects: (1) its effectiveness in increasing workers' safety awareness and making jobsites safer, (2) the consistency of its implementation, and (3) the differences when compared with other companies' safety programs. Results related to each subgroup and subgroup comparisons are shown in Table 4.

The $z$ and $p$ values for the overall acceptance in Table 4 show that the GC's workers had much higher acceptance of the safety program than the subcontractors' workers. Specifically, the GC's and subcontractors' workers had different levels of acceptance of the effectiveness of daily "huddle" meetings and the 20 non-negotiable violations. The statistical analysis results also suggested that the GC's workers thought more highly of the safety program than the subcontractors' and believed that the program made the GC's jobsite much safer. In contrast, almost no statistical difference was found between the high- and low-risk subgroups in the overall acceptance. However, different perceptions of the program's effectiveness in increasing employees' safety awareness existed between the high- and low-risk trade workers.

\subsubsection{Dimension four: general safety attitude}

In this dimension, survey questions focused on learning workers' general perceptions of safety-related work environments, which could be affected by their safety attitude or attitude of the management who particularly emphasized or did not emphasize the importance of safety. These questions included how likely they were to take risks to get a job done, and to address peers' unsafe behavior. These questions also sought workers' perceptions of risk levels and violation rates associated with high-risk building trades. Table 5 shows the comparison of general safety attitude for the two paired subgroups.

This study did not find any statistical difference in general safety attitude or in its individual items between the paired subgroups. Also, answers from the majority of workers were positive. For example, over $80 \%$ of workers in all the subgroups stated that they would not risk getting hurt to "get the job done". Approximately $92-97 \%$ of workers had a feeling of responsibility for one another's safety on jobsites. However, when asked whether they were likely to address peer workers' unsafe behavior (e.g., reporting safety violations), the percentage of positive answers dropped to $77-82 \%$.

\subsubsection{Dimension five: schedule impact}

Questions in this dimension sought workers' opinion of the safety program's impact on field operations, in particular, project schedule and productivity. This was one of the most frequently mentioned barriers for contractors and their workers to accepting the safety program and the elevated safety rules. As aforementioned, this dimension was not counted in the overall perception score of the safety program. Fig. 3 displays subgroups' perceptions of how the program impacted their work progress. It can be seen that more than $60 \%$ of each subgroup's workers thought that the program slowed down their work progress. No significant differences were found for the two paired subgroups. In terms of the degree of work progress decrease, there was also no statistical difference for the two pairs of subgroups.

\subsubsection{Overall perception of the safety program}

Table 6 shows the comparison between the paired subgroups in their overall perception scores. Each individual worker's overall perception score was computed by adding his/her average score (ranging from 0 to 1 excluding the acceptance dimension having a range from $-3 / 7$ to 1 ) from each of the first four dimensions. In this way, the overall perception score was on a scale from $-3 / 7$ to 4 , with each dimension equally weighted. It can be seen that the GC's workers had much better overall safety perception scores than the subcontractors' workers. The overall perception scores between high- and low-risk trade workers were similar.

Table 5

General safety attitude.

\begin{tabular}{|c|c|c|c|c|}
\hline \multirow[t]{2}{*}{ Response } & \multicolumn{2}{|c|}{ GC's vs. subcontractors' workers } & \multicolumn{2}{|c|}{ High-risk vs. low-risk trades } \\
\hline & GC (\% of workers) & Subcontractors (\% of workers) & High-risk (\% of workers) & Low-risk (\% of workers) \\
\hline \multicolumn{5}{|c|}{ I. Would you risk getting hurt to "get the job done"? } \\
\hline Yes $(1)$ & $20 \%$ & $14 \%$ & $17 \%$ & $16 \%$ \\
\hline $\begin{array}{l}\text { No }(0) \\
z / p \text { value (WRS) }\end{array}$ & $\begin{array}{l}80 \% \\
(-1.05) / 0.296\end{array}$ & $86 \%$ & $\begin{array}{l}83 \% \\
(-0.15) / 0.880\end{array}$ & $84 \%$ \\
\hline \multicolumn{5}{|c|}{ II. Is there a feeling of responsibility for one another's safety on the GC's jobsites? } \\
\hline Strong feeling (1) & $53 \%$ & $45 \%$ & $48 \%$ & $46 \%$ \\
\hline Somewhat feeling (0.5) & $44 \%$ & $47 \%$ & $45 \%$ & $47 \%$ \\
\hline No $(0)$ & $3 \%$ & $8 \%$ & $7 \%$ & $7 \%$ \\
\hline$z / p$ value (WRS) & $1.58 / 0.114$ & & $0.52 / 0.602$ & \\
\hline \multicolumn{5}{|c|}{ III. Is it likely for you to address an unsafe behavior or situation involving one of your peer workers? } \\
\hline Very likely (1) & $34 \%$ & $35 \%$ & $36 \%$ & $33 \%$ \\
\hline Likely $(0.5)$ & $48 \%$ & $42 \%$ & $41 \%$ & $47 \%$ \\
\hline Do not know (0) & $18 \%$ & $23 \%$ & $23 \%$ & $20 \%$ \\
\hline$z / p$ value (WRS) & $0.45 / 0.652$ & & $0.65 / 0.516$ & \\
\hline \multicolumn{5}{|c|}{ Overall for "general safety attitude" } \\
\hline$z / p$ value (WRS) & $0.52 / 0.598$ & & $0.27 / 0.782$ & \\
\hline
\end{tabular}


Does the Safety Program Slow Down Progress?

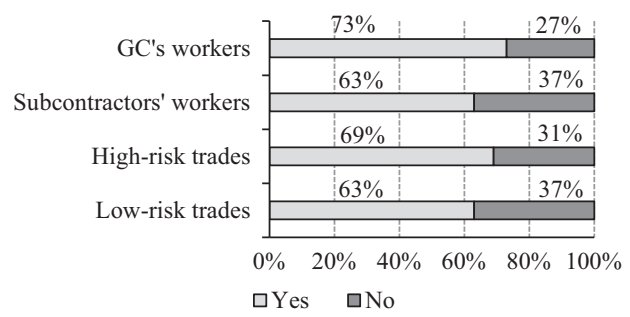

The Degree of Decrease in Work Progress

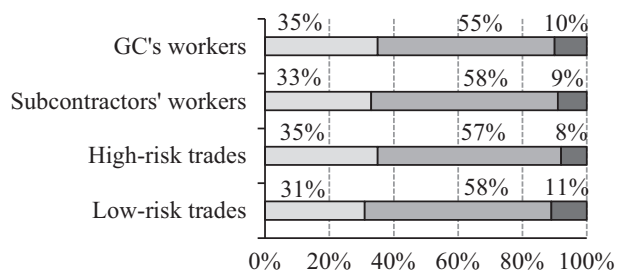

$\square$ Moderate $\square$ Somewhat/significant at times $\square$ Significant

Fig. 3. Perception of schedule impact of the safety program from different subgroups.

Table 6

Overall perception of the safety program.

\begin{tabular}{|c|c|c|c|c|}
\hline \multirow[t]{2}{*}{ Response } & \multicolumn{2}{|c|}{ GC's vs. subcontractors' workers } & \multicolumn{2}{|c|}{ High-risk vs. low-risk trades } \\
\hline & GC (\% of workers) & Subcontractors (\% of workers) & High-risk (\% of workers) & Low-risk (\% of workers) \\
\hline \multicolumn{5}{|c|}{ Overall perception Score ( $-3 / 7$ to 4$)$} \\
\hline Mean/Standard deviation & 3.11/0.55 & $2.77 / 0.65$ & $2.92 / 0.58$ & $2.86 / 0.66$ \\
\hline$p$ value (ICTM-t) & 0.000 & & 0.402 & \\
\hline
\end{tabular}

\subsection{The perception of the safety program from other subgroups}

This study also examined whether differences in perception of the safety program existed between other subgroups based on workers' familiarity with the GC's jobsites (mainly related to the GC's safety program and how the GC enforces safety), their age ranges, and safety violation records. The comparison was conducted in four scored dimensions (i.e., awareness, accountability, acceptance, and general safety attitude) and overall perception. The results are shown in Table 7.

Between the two subgroups of workers who were new to the GC's jobsites or had prior work experience with the GC, although no significant difference in overall perception was found, the latter had a higher acceptance on the safety program. This implies that workers familiar with the GC's safety program were more likely to accept the safety rules/measures than those who were new to the GC's work environment. The comparison between age groups indicates that older workers (middle-aged and above 50) had better perceptions of the safety program than young workers (below $30)$, as evidenced by the $p$ values and the trend in their means: 2.04 (below 30), 2.20 (30-49), and 2.39 (above 50). Between young workers (below 30) and middle-aged or old workers, the major difference lies in general safety attitude. It seems that young workers were more likely to take risks to get the job done and less likely to address their peers' safety issues. Statistical analysis results showed that workers who were previously asked to leave jobsites due to a safety violation tended to have better overall perception of the safety program. In particular, these workers had enhanced accountability for safety than those workers who had never been penalized by the program while maintaining the same level of acceptance to the program.

\subsection{Workers' feedback on open-ended questions}

Four open-ended questions were designed to collect workers' feedback (both positive and negative) on the safety program, its influence on workers' safety attitude change, as well as suggestions for improvement. Since there was no statistical difference in the overall perception of the safety program between high- and lowrisk trades, this study only compared workers' responses between subgroups of the GC and subcontractors. The results are displayed in Table 8 .

Table 7

Perception comparison of other subgroups.

\begin{tabular}{|c|c|c|c|c|c|c|c|c|}
\hline \multirow[t]{2}{*}{ Perception item } & \multirow[t]{2}{*}{ Statistical analysis item } & \multicolumn{2}{|c|}{ New to the GC's jobsites } & \multicolumn{3}{|l|}{ Age range } & \multicolumn{2}{|c|}{ Committed a violation } \\
\hline & & New & Not new & $<30(\mathrm{a})$ & $30-49$ (b) & $>50(\mathrm{c})$ & Yes & No \\
\hline \multirow[t]{2}{*}{ Awareness } & $z$ & $(-1.18)$ & & $(-1.12)\left(\mathrm{a} / \mathrm{b}^{\mathrm{a}}\right)$ & $(-1.87)(b / c)$ & $(-1.72)(\mathrm{a} / \mathrm{c})$ & 1.25 & \\
\hline & $p$ (WRS) & 0.238 & & 0.262 & 0.064 & 0.088 & 0.212 & \\
\hline \multirow[t]{2}{*}{ Accountability } & $\mathrm{z}$ & $(-0.24)$ & & $(-1.08)$ & 0.30 & $(-0.55)$ & 2.12 & \\
\hline & $p$ (WRS) & 0.910 & & 0.280 & 0.762 & 0.580 & 0.034 & \\
\hline \multirow[t]{2}{*}{ Acceptance } & $\mathrm{z}$ & $(-2.54)$ & & 0.67 & $(-2.99)$ & $(-1.49)$ & 0.43 & \\
\hline & $p$ (WRS) & 0.012 & & 0.504 & 0.004 & 0.138 & 0.664 & \\
\hline \multirow[t]{2}{*}{ General safety attitude } & $\mathrm{z}$ & 0.10 & & $(-3.68)$ & 0.15 & $(-2.64)$ & -0.73 & \\
\hline & $p$ (WRS) & 0.918 & & 0.000 & $0.884(\mathrm{~b} / \mathrm{c})$ & 0.010 & 0.468 & \\
\hline \multirow[t]{4}{*}{ Overall perception } & Mean & 2.74 & 2.92 & 2.04 & 2.20 & 2.39 & 2.50 & 2.14 \\
\hline & Std. & 0.73 & 0.62 & 0.66 & 0.65 & 0.53 & 0.63 & 0.68 \\
\hline & $t$ & 1.87 & & $1.91(\mathrm{a} / \mathrm{b})$ & $2.01(b / c)$ & $3.33(\mathrm{a} / \mathrm{c})$ & 2.65 & \\
\hline & $p($ ICTM-t) & 0.062 & & 0.058 & 0.046 & 0.000 & 0.008 & \\
\hline
\end{tabular}

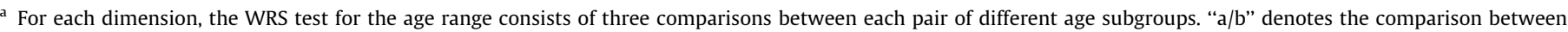
subgroups "a" and "b".

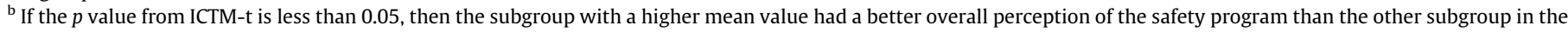
pair comparison.
} 
Table 8

Comparison of workers' responses from subgroups of the GC and subcontractors.

\begin{tabular}{|c|c|c|c|c|c|}
\hline \multirow[t]{2}{*}{ Items } & \multirow[t]{2}{*}{ Responses } & \multicolumn{2}{|c|}{ GC's workers $(N=110)$} & \multicolumn{2}{|c|}{$\begin{array}{l}\text { Subcontractors' workers } \\
(N=240)\end{array}$} \\
\hline & & $\begin{array}{l}\text { No. of } \\
\text { responses }\end{array}$ & $\begin{array}{l}\% \text { of } \\
\text { responses }\end{array}$ & $\begin{array}{l}\text { No. of } \\
\text { responses }\end{array}$ & $\begin{array}{l}\% \text { of } \\
\text { responses }\end{array}$ \\
\hline \multirow[t]{9}{*}{ Positive feedback } & $\begin{array}{l}\text { Feeling safer on jobsites with less accidents and more safety } \\
\text { awareness }\end{array}$ & 21 & $64 \%$ & 30 & $60 \%$ \\
\hline & Increased safety awareness & 4 & $12 \%$ & 3 & $6 \%$ \\
\hline & Safety boosted by strict rules & 4 & $12 \%$ & 1 & $2 \%$ \\
\hline & Enhanced communication on safety & 2 & $6 \%$ & 2 & $4 \%$ \\
\hline & Keeping workers safe with required PPE & 1 & $3 \%$ & 13 & $26 \%$ \\
\hline & Caring about peer workers & 1 & $3 \%$ & 1 & $2 \%$ \\
\hline & Subtotal & 33 & $100 \%$ & 50 & $100 \%$ \\
\hline & Responses/no. of workers surveyed & 0.30 & & 0.21 & \\
\hline & $z$ score $/ p$ value & $1.87 / 0.031$ & & & \\
\hline \multirow[t]{9}{*}{ Negative feedback } & Taking longer and losing productivity & 17 & $28 \%$ & 13 & $17 \%$ \\
\hline & Feeling negative on safety rules & 11 & $18 \%$ & 24 & $32 \%$ \\
\hline & Inconsistency of enforcement & 10 & $16 \%$ & 15 & $20 \%$ \\
\hline & Loss of positive reinforcement & 5 & $8 \%$ & 1 & $1 \%$ \\
\hline & Negative perception on penalties & 3 & $5 \%$ & 11 & $15 \%$ \\
\hline & Other negative feedback $k^{\mathrm{b}}$ & 15 & $25 \%$ & 11 & $15 \%$ \\
\hline & Subtotal & 61 & $100 \%$ & 75 & $100 \%$ \\
\hline & Responses/no. of workers surveyed & 0.55 & & 0.31 & \\
\hline & $z$ score $/ p$ value & 4.13/0.000 & & & \\
\hline \multirow[t]{11}{*}{ Suggestions for improvement } & Enhancing enforcement and consistency & 8 & $20 \%$ & 17 & $27 \%$ \\
\hline & More education/training and stressing responsibility & 6 & $15 \%$ & 4 & $6 \%$ \\
\hline & The use of incentives & 6 & $15 \%$ & 1 & $2 \%$ \\
\hline & Lightening up/lighter penalties & 3 & $8 \%$ & 10 & $16 \%$ \\
\hline & Clear rules & 3 & $8 \%$ & 4 & $6 \%$ \\
\hline & Suggestions on specific safety rules & 3 & $8 \%$ & 15 & $24 \%$ \\
\hline & Enhancing communication \& adding meetings & 2 & $5 \%$ & 4 & $6 \%$ \\
\hline & Others suggestions & 9 & $23 \%$ & 8 & $13 \%$ \\
\hline & Subtotal & 40 & $100 \%$ & 63 & $100 \%$ \\
\hline & Suggestions/no. of workers surveyed & 0.36 & & 0.26 & \\
\hline & $z$ score $/ p$ value & $1.93 / 0.027$ & & & \\
\hline \multirow{11}{*}{$\begin{array}{l}\text { Impact on employees' attitude toward } \\
\text { safety? }\end{array}$} & Increased safety awareness & 11 & $17 \%$ & 30 & $22 \%$ \\
\hline & Enhanced accountability & 11 & $17 \%$ & 18 & $13 \%$ \\
\hline & Good safety attitude & 7 & $11 \%$ & 27 & $20 \%$ \\
\hline & Caring for co-workers' safety & 4 & $6 \%$ & 6 & $4 \%$ \\
\hline & General positive comments & 7 & $11 \%$ & 9 & $7 \%$ \\
\hline & Bad attitude/negative comments & 21 & $33 \%$ & 21 & $15 \%$ \\
\hline & No attitude change caused by this program & 3 & $5 \%$ & 27 & $20 \%$ \\
\hline & Subtotal & 64 & $100 \%$ & 138 & $100 \%$ \\
\hline & Subtotal for positive comments & 40 & & 90 & \\
\hline & Positive comments/no. of workers surveyed & 0.36 & & 0.38 & \\
\hline & $z$ score $/ p$ value & $-0.20 / 0.421$ & & & \\
\hline
\end{tabular}

a The top three most common responses based on the percentage were italicized in the table. The general comments were not counted in the ranking.

b Other negative feedback includes general negative comments such as "Nobody really likes it".

There were 33 (0.30 comment per worker) and 50 (0.21 comment per worker) positive comments from the GC's and subcontractors' workers, respectively. Most of the GC's and subcontractors' workers ( $60 \%$ or greater of the total responses) felt that the jobsites were safer due to the program. The GC's workers thought highly of the increased safety awareness and strict safety rules while subcontractors' workers liked the enforced personal protective equipment (PPE) that kept them safe on the jobsites. The GC's and subcontractors' workers provided 61 (0.55 comment per worker) and 75 (0.31 comment per worker) negative comments, respectively. The three most common answers in both subgroups were the same: negative feelings about the safety rules, taking longer and losing productivity, and inconsistency of enforcement. While more subcontractors' workers (32\%) had complaints regarding the boosted safety rules, more of the GC's workers (28\%) felt that the launch of the program negatively impacted work progress and productivity, which was consistent with the early research finding in Section 4.2.5. The statistical analysis results showed that the GC's workers offered more positive and negative feedback than subcontractors' workers.
Among the suggestions for improvement, both groups recommended enhancing the enforcement of the program and its consistency. The GC's workers preferred the use of safety incentives and training/education to improve the program. Subcontractors' workers also preferred less severe penalties but had different suggestions on specific safety rules (e.g., providing side shields for those who wear eye glasses, dealing with congestion on jobsites, etc.) for continual improvement. This might be due to the different safety rules enforced by individual subcontractors, which varied from the GC's safety program to some degree. It also turned out that the GC's workers offered statistically more suggestions for improvement than subcontractors' workers.

When asked whether the program affected employees' attitude toward safety, increased safety awareness, good safety attitude, and enhanced accountability were the three most frequently mentioned items in both subgroups. Specifically, more subcontractors' workers thought that the program improved their safety awareness and attitude. The GC's workers saw increased awareness and accountability of safety. No statistical difference was found between these two subgroups in the safety program's positive impact on employees' safety attitude. 


\section{Discussion}

This study found that workers' awareness of the safety program, especially detailed safety rules, had a relationship with the effectiveness of education they received. Educating workers about a safety program in a way that combined training with visuals was more effective than using training or visuals alone. Considering only around $60 \%$ of the surveyed workers learned useful information from visuals that were present on the jobsites, it would be helpful for the GC to highlight these learning tools (e.g., where the posters are located) during the safety orientation for employees who are new to the jobsites.

It was found that most of the GC's and subcontractors' workers knew the right consequence of a first-time violation, but were not aware of the consequence of a second-time violation. This impaired their safety accountability. This was probably due to the fact that a limited number of second-time violations (28 out of 939 total violations in 27 months) occurred on the jobsites, so workers had less or no exposure to the related penalty. To ensure workers' complete understanding of the program's accountability system and their safety responsibility, the GC should frequently communicate the related information to workers through "huddle" meetings and other safety meetings required. Otherwise, when such a consequence occurs, the affected worker(s) will be totally surprised, resulting in a feeling of unfairness.

The GC's workers were found to have significantly higher acceptance of the safety program than subcontractors' workers, showing that it is important for a GC to improve its control on subcontractors' workers and increase their safety commitment. This could be achieved through providing more effective education as well as building a long-term business relationship or partnership with subcontractors, especially those who had good safety performance when working with the GC. On the other hand, involving subcontractors in the development and improvement of the safety program can also increase their acceptance of the program.

Although the GC's safety program encourages workers to report safety violations of their peers, this only happened to $2 \%$ of the total cases (Chen and Jin, 2012). The fear of retaliation from coworkers may be a potential reason (Heid, 2010). Since the survey results showed that over $90 \%$ of the workers had a feeling of responsibility for peer workers' safety, site management should strongly and constantly encourage them to take care of each other (i.e., reminding others of safety violations or hazardous conditions) during safety orientations and other safety meetings. Doing so will also help create a heathy and safer work environment.

This study found that older workers (especially those above 50) had better perceptions of the safety program as well as better safety attitude, which was consistent with the study of Siu et al. (2003) in which older workers had more positive safety attitude toward housekeeping, safety equipment, and support from management/supervisor. Similarly, Fang et al. (2006) also found that employees who were older and married had a more positive perception of safety climate than those who were young and single. These findings suggested that more attention and safety training/ education need to be given to young workers. In addition, older workers with good safety attitude and behavior can be assigned as safety mentors for young workers.

It is worth noting that the element of accountability for 20 nonnegotiables takes a BBS approach, which have received some criticism for shifting safety responsibilities to workers, solely blaming workers' unsafe behaviors as causes of accidents, the potential for management misconducts, etc. (Walker, 2003; Brown and Barab, 2007; Mullins, 2007). However, in this study, the researchers had not heard any complaint or noticed any sign of misconduct or inappropriate manipulation of safety violation data by the GC's man- agement team except some inconsistencies in enforcement. It seemed that the BBS component did not cause any major problems in this case due to that the safety program was indeed a genuine attempt of the GC to keep workers safe as agreed by more than $70 \%$ of workers surveyed. As mentioned by one of the workers, "from the ones that really take it to heart like myself, it is nice to know our company cares so much and it takes the time to put together a program that makes sure I go home to my family the way I come to work". Another subcontractor's worker said: "This is a pain, but it's a good thing. I wish we had a program like this".

Through the questionnaire survey, this study identified variations in workers' perceptions of the GC's safety program between selected subgroups, especially the GC and subcontractors. The findings helped understand why the program was more effective among the GC's workers than subcontractors', but did not solve all the puzzles. As stated in Section 1.1, many factors could influence subcontractor safety performance. However, consistently and persistently enforcing safety by GCs and CM firms would positively change subcontractors' safety culture, climate, and attitude in the long run, which will have positive impact on their safety performance. Since all the research findings have been transferred to the GC for assessing and improving this ongoing program, the researchers will follow up with the GC to see whether subcontractor safety performance improves over time after continuous enforcement of the studied program.

\section{Conclusions}

The extensive use of subcontracting in the construction industry has raised significant safety concerns among main contractors, researchers, and safety and health regulators. Although some GCs or CM firms took active roles in helping subcontractors improve safety performance, the effectiveness of the safety measures implemented by GCs or CM firms was often compromised by a diverse workforce of subcontractors. The study presented in this paper aimed to (1) test the hypothesis that workers' perceptions of a GC's safety program varied between subgroups, (2) identify causes of such variations, and (3) offer insights for contractors to improve the effectiveness of their safety programs. The subgroups compared included: (1) the GC's and subcontractors' workers, (2) highand low-risk trades, and (3) subgroups based on other criteria such as age. In this study, a 5-dimension 28-item questionnaire was administered to 350 workers on the GC's jobsites through faceto-face surveys. Based on the collected information, perception scores were calculated for subgroups and statistical comparisons were performed to examine subgroup differences. The major research findings are concluded as follows:

The GC's workers were proved to have better overall perception of the program than that of subcontractors. In particular, the GC's workers had better perception scores in the awareness and acceptance dimensions, but not in accountability and general safety attitude. The better awareness among the GC's workers was due to the enhanced safety education (i.e., learning the program from classroom training, orientation video, and visuals) they received and their repeated exposure to the program by working for the same GC. This finding emphasized the necessity of providing subcontractors with enhanced and continuous training on a GC's safety program. Hiring subcontractors that have repeatedly worked for the same GC is also a good safety management practice.

No statistical difference in the overall perception of the program or each perception dimension was found between high- and lowrisk trade workers, suggesting that workers' perceptions of the safety program had no relationship with the risk levels of their trades. For other subgroups compared, several statistical 
differences were identified in individual perception dimensions or the overall perception. Specifically, workers who had repeatedly worked for the GC had better acceptance of the safety program than those who were new to the GC's jobsites. Older workers tended to have better safety attitude and overall perception than younger workers, showing the potential for implementing a safety mentoring program to pair them up. Surprisingly, workers who had been sent home due to safety violations had better perception of the safety program and accountability. This finding will help increase site management's confidence in enforcing safety by alleviating the management concern that sending workers home might lower their acceptance of a safety program and undermine GCs' safety efforts.

The feedback from open-ended questions showed that most of the GC's and subcontractors' workers felt safer at the GC's jobsites with this site-wide safety program. The enforced use of PPE was highly valued by subcontractors' workers while the inconsistency of enforcement was one of their main concerns, which needs to be properly addressed by the GC. More of subcontractors' workers offered suggestions on specific safety rules that might be more practical for the work they perform, highlighting the importance of involving subcontractors in developing and continuously improving a GC's safety program. Overall, subcontractors' workers offered statistically fewer comments and suggestions than the GC's workers. To address this issue, GCs should strongly encourage subcontractors' employees to give feedback as well as provide a communication channel and potential incentives for people doing so.

\section{References}

Aksorn, T., Hadikusumo, B.H.W., 2008. Critical success factors influencing safety program performance in Thai construction projects. Saf. Sci. 46, 709-727.

Baradan, S., Usmen, M.A., 2006. Comparative injury and fatality risk analysis of building trades. J. Constr. Eng. Manage. 132 (5), 533-539.

Bridge, P.D., Sawilowsky, S.S., 1999. Increasing physician's awareness of the impact of statistics on research outcomes: comparative power of the t-test and Wilcoxon Rank-Sum test in small samples applied research. J. Clin. Epidemiol. 52 (3), 229-235.

Brown, G.D., Barab, J., 2007. "Cooking the books" - behavior-based safety at the San Francisco Bay Bridge. New Solut. 17 (4), 311-324.

B-Safe Management Solutions Inc. (BSMS), 2013. Industry survey on BBS Demographics. <http://www.behavioral-safety.com/free-behavioral-safetyresource-center/about-behavioral-safety/latest-bbs-survey-results/74industry-survey-on-bbs> (22.02.13).

Budworth, N., 1997. The development and evaluation of a safety climate measure as a diagnostic tool in safety management. J. Inst. Occup. Saf. Health 1, 19-29.

Canter, M.R., 1993. Resource Management for Construction. Macmillan Press, Basingstoke, Hampshire and London.

Centers for Disease Control and Prevention (CDC), 1999. Providing Safety and Health Protection for a Diverse Construction Workforce: Issues and Ideas. <http://www.cdc.gov/niosh/docs/99-140/> (14.08.14).

Centers for Disease Control and Prevention (CDC), 2008. National Construction Agenda for Occupational Safety and Health Research and Practice in the U.S. Construction Sector. <http://www.cdc.gov/niosh/nora/comment/agendas/ construction/pdfs/ConstOct2008.pdf> (24.10.11).

Chen, Q., Jin, R., 2012. Safety4Site commitment to enhance jobsite safety management and performance. J. Constr. Eng. Manage. 138 (3), 509-519.

Choudhry, R.M., Fang, D., Mohamed, S., 2007a. The nature of safety culture: a survey of the state-of-the-art. Saf. Sci. 45, 993-1012.

Choudhry, R.M., Fang, D., Mohamed, S., 2007b. Developing a model of construction safety culture. J. Constr. Eng. Manage. 23 (4), 207-212.

Cooper, M.D., 2003. Behavior based safety still a viable strategy. Saf. Health Apr., $46-48$

Cox, S.J., Cheyne, A.J.T., 2000. Assessing safety culture in offshore environments. Saf. Sci. 34, 111-129.

DePasquale, J.P., Geller, E.S., 1999. Critical success factors for behavior-based safety: a study of twenty industry-wide applications. J. Saf. Res. 30 (4), 237-249.

Dong, X., Platner, J.W., 2004. Occupational fatalities of Hispanic construction workers from 1992 to 2000. Am. J. Ind. Med. 45, 45-54.

EU-OSHA, 2006. "Safe Start" campaign to Protect Young Workers. <https:// osha.europa.eu/fop/czech-republic/en/news/tiskove_zpravy_eu/ tz20062006.php> (02.07.09)

Fabrega, V., Starkey, S., 2001. Fatal occupational injuries among Hispanic construction workers of Texas, 1997 to 1999. Hum. Ecol. Risk Assess. 7 (7), 1869-1883.

Fang, D., Chen, Y., Wong, L., 2006. Safety climate in construction industry: a case study in Hong Kong. J. Constr. Eng. Manage. 132 (6), 573-584.
Garner, C., 2004. Construction safety program essentials. In: Hill, D.C. (Ed.), Construction Safety Management and Engineering, first ed. American Society of Safety Engineers, Des Plaines, IL.

Geller, E.S., 1998a. Understanding Behavior-Based Safety: Step-By-Step Methods to Improve Your Workplace, second ed. J.J. Keller \& Associates Inc, Neenah, WI.

Geller, E.S., 1998b. People-Based Safety: The Source, second ed. Coastal Training Technologies Corp, Virginia Beach, VA.

Geller, E.S., Wiegand, D.M., 2005. People-based safety: exploring the role of personality in injury prevention. Prof. Saf. 50 (12), 28-36.

Gillen, M., Baltz, D., Gassel, M., Kirsch, L., Vaccaro, D., 2002. Perceived safety climate, job demands, and coworker support among union and nonunion injured construction workers. J. Saf. Res. 33 (1), 33-51.

Glendon, A.I., Litherland, D.K., 2001. Safety climate factors, group differences, and safety behavior in road construction. Saf. Sci. 39 (3), 157-188.

Goldenhar, L.M., Moran, S.K., Colligan, M., 2001. Health and safety training in a sample of open-shop construction companies. J. Saf. Res. 32, 237-252.

Heid, M. 2010. Metro Employee Survey Finds Safety Violations, Fear of Peer Retaliation. Washington Examiner, October 27, 2010.

Hinze, J., Figone, L., 1988. Subcontractor safety as influenced by general contractors on small and medium sized projects. Source Document 38, Construction Industry Institute, Austin, TX.

Hinze, J., Gambatese, J., 2003. Factors that influence safety performance of specialty contractors. J. Constr. Eng. Manage. 129 (2), 159-164.

Hinze, J., Talley, D., 1988. Subcontractor Safety as Influenced by General Contractors on Large Projects. Source Document 39, Construction Industry Institute, Austin, TX

Hinze, J., Tracey, A., 1994. The contractor-subcontractor relationship: the subcontractor's view. J. Constr. Eng. Manage. 120 (2), 274-287.

Hislop, R.D., 1991. A construction safety program. Prof. Saf. 36 (9), 14-20.

Holzemer, M., Tommelein, I.D., Lin, S.L., 2000. Materials and information flows for HVAC ductwork fabrication and site installation. In: Proceedings of the 8th Annual Conference of the International Group for Lean Construction, Brighton, U.K.

Hsieh, T.Y., 1998. Impact of subcontracting on site productivity: lessons learned in Taiwan. J. Constr. Eng. Manage. 124 (2), 91-100.

Ivensky, V., 2008. Safety risk management of subcontractors: what is a standard of care? Prof. Saf. 53 (1), 43-46.

Johnson, R.A., 2005. Miller \& Freund's Probability and Statistics for Engineers, seventh ed. Pearson Prentice Hall, Upper Saddle River, NJ, pp. 260-272, 304, 397-439.

Johnstone, R., Mayhew, C., Quinlan, M., 2000. Outsourcing risks? The regulation of occupational health and safety where subcontractors are employed. Comp. Lab. L. Pol'y J. 22, 351-393.

Landin, A., 1995. Specialist contractor's approach to quality management in Sweden. Build. Res. Inf. 23 (2), 110-113.

Lee, T., Harrison, K., 2000. Assessing safety culture in nuclear power stations. Saf. Sci. 34, 61-97.

Lingard, H., Rowlinson, S., 1998. Behavior-based safety management in Hong Kong's construction industry: the results of a field study. Constr. Manage. Econ. 16 (4), 481-488.

Mah, C., 2007. Improved Safeguards for Young and New Workers. Construction Business November/December, 58-60.

Mason, S., Simpson, G., 1995. Measuring safety attitudes to target management actions. Saf. Health Pract., 17-20.

McDonald, N., Corrigan, S., Daly, C., Cromie, S., 2000. Safety management systems and safety culture in aircraft maintenance organizations. Saf. Sci. 34, 151-176.

Mecca, S., 1999. As sequences flow: proposal of organizational rules for "Lean Construction" management. In: Proceedings of the 7th Annual Conference of the International Group for Lean Construction, Berkeley, CA, pp. 399-410.

Mohamed, S., 2003. Scorecard approach to benchmarking organizational safety culture in construction. J. Constr. Eng. Manage. 129 (1), 80-88.

Mullins, S., 2007. Behavior based safety - a worker perspective. In: Proceedings of the Behavioral Based Safety in Heavy Industries, Melbourne, Australia.

Nieva, V.F., Sorra, J., 2003. Safety culture assessment: a tool for improving patient safety in healthcare organizations. Qual. Saf. Health Care 12, 7-23.

Occupational Safety and Health Administration (OSHA), 2011. Construction Focus Four. <http://www.osha.gov/dte/outreach/construction/focus_four.html> (28.04.11)

Oh, J.I.H., Sol, V.M., 2008. The policy program improving occupational safety in The Netherlands: an innovative view on occupational safety. Saf. Sci. 46 (2), 155163.

Quinlan, M., 2003. Flexible Work and Organizational Arrangements: Regulatory Problems and Responses. National Research Centre for OHS Regulation, Canberra, Australia.

Shaw, M., 1998. Promotion of occupational safety and health for small and medium sized enterprises - Canadian experience. Hong Kong J. Green Cross 8, 40-45.

Silberberg, R., 1991. Keynote address: the subcontractor and Australia's housing industry: an example of world class competitiveness. In: Nicholls Society, H.R. (Ed.), the Law and the Labor Market. <http://www.hrnicholls.com.au/archives/ vol11/vol11-1.php> (20.10.11).

Siu, O.l., Phillips, D.R., Luung, T.W., 2003. Age differences in safety attitudes and safety performance in Hong Kong construction workers. J. Saf. Res. 34, 199-205.

Suruda, A., Philips, P., Lillquist, D., Sesek, R., 2003. Fatal injuries to teenage construction workers in the US. Am. J. Ind. Med. 44 (5), 510-514.

Swain, B., Martin, J., 2000. Applying lean thinking principles in the UK roofing and cladding Industry. In: Proceedings of the 8th Annual Conference of the International Group for Lean Construction, Brighton, U.K. 
Tam, C.M., Fung, I.W.H., 1998. Effectiveness of safety management strategies on safety performance in Hong Kong. Constr. Manage. Econ. 16, 49-55.

Tam, C.M., Zeng, S.X., Deng, Z.M., 2004. Identifying elements of poor construction safety management in China. Saf. Sci. 42, 569-586.

Toole, T.M., 2002. Construction site safety roles. J. Constr. Eng. Manage. 128 (3), 203-210.

Walker, C., 2003. Behavior Based Safety Programs. Health and Safety Department, Toronto, Ontario.

Waring, A., 1992. Developing a safety culture. Saf. Health Pract., 42-44.

Welch, L., Goldenhar, L.M., Hunting, K.L., 2000. Women in construction: occupational health and working conditions. J. Am. Med. Wom. Assoc. 55 (2), 89-92.

Whitten, B., 1991. How to Hire and Supervise Subcontractors. Home Builder Press, Washington, D.C.

Williams, J.H., 2003. People-based safety. Prof. Saf. 48 (2), 32-36.
Wilson, J.M., Koehn, E., 2000. Safety management: problems encountered and recommended solutions. J. Constr. Eng. Manage. 126 (1), 77-79.

Windau, J., Meyer, S., 2005. Occupational injuries among young workers. Mon. Labor Rev., 11-23.

Wong, K.W. So, L, 2004. Restriction of the multi-layers subcontracting practice in Hong Kong - Is it an effective tool to improve safety performance of the construction industry? In: Rowlinson, S. (Ed.), Construction Safety Management Systems. Taylor \& Francis, NY, pp. 137-149.

Zohar, D., 2000. A group-level model of safety climate: testing the effect of group climate on micro-accidents in manufacturing job. J. Appl. Psychol. 85 (4), 587596.

Zhou, Q Fang, D., Wang, X, 2008. A method to identify strategies for the improvement of human safety behavior by considering safety climate and personal experience. Saf. Sci. 46 (10), 1406-1419. 